\title{
Adaptive Coping and Spirituality as a Resource in Cancer Patients
}

\author{
Arndt Büssing Thomas Ostermann Peter F. Matthiessen \\ Arbeitsgruppe Spiritualität und Krankheitsumgang, Lehrstuhl für Medizintheorie und Komplementärmedizin, \\ Universität Witten/Herdecke, Germany
}

\section{Key Words}

Religion · Spirituality · Medicine · Cancer · Coping

\section{Summary}

Aim: We intended to clarify which strategies to control their diseases were utilized by patients with chronic diseases and whether they are convinced that spirituality/religiosity (SpR) may offer some beneficial effects. Patients and Methods: We investigated elderly German insurants and outpatients with chronic diseases with the SpREUK and AKU questionnaires. Results: Patients with chronic diseases relied on adaptive coping styles which refer to both external help (Trust in Medical Help, Search for Alternative Help, Trust in God's Help) and internal powers/virtues (Conscious and Healthy Living, Perspectives and Positive Attitudes). Reappraisal (IIIness as Chance) was strongly connected with Trust in God's Help, which was of relevance particularly for female cancer patients. Compared to patients with other chronic diseases, cancer patients were significantly more in Search for Meaningful Support, had Trust in Higher Source and a Positive Interpretation of Disease. Women with breast cancer had significantly higher interest in Search for Meaningful Support and Positive Interpretation than patients with prostate cancer. The SpR attitudes and convictions were significantly influenced by gender, SpR self-categorization, and educational level. Conclusion: Particularly women with breast cancer refer to $\mathrm{SpR}$ issues and existential practices in order to better cope with their illness. In medical context, however, these needs are often neither recognized nor addressed.
Schlüsselwörter

Religion · Spiritualität · Medizin · Krebs · Coping

\section{Zusammenfassung}

Fragestellung: Welche Strategien zur Kontrolle ihrer Erkrankung verwenden Patienten mit chronischen Erkrankungen, und sind sie davon überzeugt, dass Spiritualität/Religiosität ( $\mathrm{SpR}$ ) für sie von Nutzen sein könnten? Patienten und Methoden: Um diese Fragen zu beantworten, wurden ältere deutsche Versicherte und ambulante Patienten mit chronischen Erkrankungen mit Hilfe der SpREUK- und der AKU-Fragebögen untersucht. Ergebnisse: Es zeigte sich, dass chronische Patienten adaptive Coping-Stile benutzen, die sich sowohl auf externale helfende Instanzen beziehen (z.B. Vertrauen in medizinische Hilfe, Suche nach alternativer Hilfe, Vertrauen in Gottes Hilfe) als auch auf internale Kräfte und Fähigkeiten (z.B. Bewusste und gesunde Lebensführung, Perspektiven und positive Einstellungen). Die Krankheitsneubewertung (Krankheit als Chance) zeigte einen deutlichen Zusammenhang mit Vertrauen in Gottes Hilfe, und ist insbesondere für weibliche Krebspatienten von Bedeutung. Die angesprochenen adaptiven Coping-Stile der Krebspatienten waren insbesondere von Geschlecht und Alter abhängig. Frauen mit Brustkrebs hatten signifikant höhere Scores für Suche nach Sinn gebender Rückbindung und Positive Krankheitsinterpretation als männliche Patienten mit Prostatakarzinom. Diese Einstellungen waren signifikant abhängig vom Geschlecht, dem Schulabschluss und der SpR-Selbsteinschätzung. Schlussfolgerung: Insbesondere Brustkrebspatientinnen bezogen sich auf SpRInhalte und eine existenzialistische Praxis, um mit ihrer Krankheit besser umgehen zu können. In vielen Fällen jedoch werden diese Bedürfnisse im medizinischen Kontext weder wahrgenommen noch angesprochen.

\begin{tabular}{ll}
\hline KARGER & ( ) 2007 S. Karger GmbH, Freiburg \\
Fax +497614520714 & Accessible online at: \\
$\begin{array}{l}\text { E-mail Information@Karger.de } \\
\text { www.karger.com }\end{array}$ & www.karger.com/brc
\end{tabular}

\section{KARGER}

www.karger.com
PD Dr. med. Arndt Büssing

Institut für Medizintheorie und Komplementärmedizin

Universität Witten/Herdecke

Gerhard-Kienle-Weg 4, 58313 Herdecke, Germany

Tel. +49 2330 623-246, Fax -358

E-mail Arndt.Buessing@uni-wh.de 


\section{Introduction}

There are several concepts of how a person deals with problems, stress, and illness. Although the differentiation between problem-focused coping and emotion-focused coping is widely acknowledged, there are several distinct ways to solve problems or to regulate emotions. Nevertheless, most patients with chronic diseases, particularly cancer patients, are unable to solve their 'problem' and have to find strategies to adapt to a long-lasting illness and to find ways to maintain physical, emotional, and spiritual health despite of an unclear prognosis. In fact, life-threatening diseases confront patients with the question of the meaning and purpose of life, and for several of them spirituality/religiosity $(\mathrm{SpR})$ is regarded as a source to rely on in such times of need, e.g. to relieve stress, retain a sense of control, and maintain hope and sense of meaning and purpose in life [1].

Within the last 20 years, an increasing number of published studies, commentaries, and reviews have examined the connection between $\mathrm{SpR}$, health and quality of life, and its potential to prevent, heal or cope with disease [1-6]. These studies indicate that religious involvement is related to better mental and physical health, improved coping with illness, and improved medical outcomes [7]. Moreover, SpR beliefs influence medical decisions made by patients and their families [7], and unresolved religious or spiritual struggles can have a negative impact on the course of patients' illnesses after hospital discharge [8]. Thus, medical doctors should care about the spiritual needs of their patients, even if they do not share these believes.

In breast cancer patients Levine and Targ [9] found significant correlations of spirituality and spiritual well-being with functional well-being rather than physical well-being, but items pertaining to meaning and peace tended to correlate significantly with physical well-being. Spiritual well-being offers some protection against hopelessness and despair in terminally ill patients [10-13]. There is less doubt that values and goals are important contributors to life satisfaction, physical and psychological health, and that goals are what gives meaning and purpose to people's lives [14]. But in face of a life-threatening disease, do patients find meaning and purpose in their life? Which strategies to control their diseases do they utilize, and are they really convinced that SpR may offer some beneficial effects? According to the concept of 'external locus of control' by Rotter [15] and Levenson [16], patients will ask medical specialists for help and additionally may trust in a helping God. However, in several cases patients may lose faith in their religious beliefs and seek for alternatives.

To address these questions we analyzed adaptive styles to cope with disease (respectively to maintain health) in elderly German insurants ('Die Continentale Versicherung') and in patients with chronic diseases from two hospitals and analyzed SpR intentions and attitudes in a group of chronic patients from several outpatient clinics.

\section{Materials and Methods}

\section{Patients}

All individuals were informed of the purpose of the study, were assured of confidentiality, and gave informed consent to participate. We analyzed two pools: The first consisted of 6,312 individuals from a survey with elderly German insurants ('Die Continentale Versicherung', $\mathrm{n}=5,830$ ) and patients with chronic diseases recruited at the Department of Internal and Integrative Medicine at the Essen-Mitte Clinics $(\mathrm{n}=329)$ and at the pain outpatient clinic of the Communal Hospital in Herdecke $(n=153)$. The second pool consisted of 719 patients recruited at the tumor outpatient clinic, the multiple sclerosis outpatient clinic, the pain outpatient clinic of the Communal Hospital in Herdecke, the Department of Internal and Integrative Medicine at the Essen-Mitte Clinics, a medical ward in Wuppertal, and some other medical centers in Germany.

\section{Demographic Characteristics}

Pool 1: 6,312 individuals with a mean age of $63.9 \pm 11.6$ years $(34 \%$ female, $66 \%$ male). With respect to the educational level, $20 \%$ had a secondary education ('Hauptschule'), 22\% a junior high school education ('Realschule'), 51\% a high school education ('Gymnasium'), and $8 \%$ other. Most were married (71\%), others lived with a partner not married with (5\%), while $12 \%$ were widowed, $6 \%$ lived alone, $6 \%$ were divorced. $64 \%$ regarded themselves as healthy, $17 \%$ had chronic diseases, $11 \%$ acute diseases, and $8 \%$ had cancer $(\mathrm{n}=505)$.

Pool 2: 719 patients with a mean age of $54.0 \pm 14.6$ years $(76 \%$ female, $24 \%$ male). Most were married $(53 \%)$ or lived with a partner not married with $(10 \%), 13 \%$ lived alone, $13 \%$ were divorced, and $10 \%$ were widowed. $25 \%$ had cancer $(n=180), 10 \%$ multiple sclerosis, $21 \%$ other chronic diseases, $3 \%$ acute diseases, and $42 \%$ chronic pain diseases. Most had a course of disease > 5 years (37\%), 12\% 3-5 years, 24\% 1-3 years, $13 \% 6-12$ months, and $14 \%<6$ months. In this pool, the educational level was much more heterogeneous: $34 \%$ had a secondary education ('Hauptschule'), 27\% a junior high school education ('Realschule'), $27 \%$ a high school education ('Gymnasium'), and $13 \%$ other. Most of them had a Christian affiliation $(80 \%), 11 \%$ other religious affiliations, and $9 \%$ had none. $34 \%$ reported themselves as religious, but not spiritual $(\mathrm{R}+\mathrm{S}-), 25 \%$ as both religious and spiritual $(\mathrm{R}+\mathrm{S}+), 9 \%$ as spiritual, but not religious $(\mathrm{R}-\mathrm{S}+)$, and $32 \%$ as neither religious nor spiritual (R-S-).

\section{Measures and Statistical Analysis}

In order to examine how patients with severe diseases view the impact of SpR on their health and how they cope with illness, we have developed the SpREUK questionnaire [17-21], which measures SpR attitudes and convictions and appears to be a good choice for assessing a patient's interest in spiritual concerns which is not biased for or against a particular religious commitment. This tool relies on essential motifs found in counselling interviews with chronic disease patients (i.e. trust/faith, source/ hold, message/change) [22]. For this study we used the SpREUK version SF-26 (scale 4 with 9 items instead of 15 items). To avoid an intermix of attitudes, convictions, and practices, the distinct forms and frequencies of $\mathrm{SpR}$ practices were measured with an additional manual, the SpREUK-P questionnaire, which differentiates spiritual, religious, existentialistic, and philosophical practices [20, 23].

Adaptive coping styles were measured with the AKU questionnaire [20, 24]. The theoretical concept behind the original 45-item pool of the AKU was the differentiation of active and adaptive coping styles, such as to create favorable conditions, search for information, medical support, religious support, social support, initiative spirit, and positive (re)interpretation of disease. A revalidation of the questionnaire with the individuals of pool 1 confirmed quality and structure of the AKU questionnaire in its version 1.2 (table 1), which thus can be used for this investigation. 
Table 1. Mean values and reliability parameters of the AKU 1.2 questionnaire (pool 1)

\begin{tabular}{|c|c|c|c|c|c|c|}
\hline & & $\begin{array}{l}\text { Mean values } \\
\pm \text { SD }\end{array}$ & $\begin{array}{l}\text { Difficulty } \\
\text { index (0.66) }\end{array}$ & $\begin{array}{l}\text { Factor } \\
\text { loading }\end{array}$ & $\begin{array}{l}\text { Corrected } \\
\text { item-total } \\
\text { correlation }\end{array}$ & $\begin{array}{l}\text { Alpha if } \\
\text { item deleted } \\
(\alpha=0.876)\end{array}$ \\
\hline \multicolumn{7}{|c|}{ 1. Trust in God's Help ( $\alpha=0.914 ; 14.5 \%$ of variance) } \\
\hline a36 & Strong belief that god will help & $2.30 \pm 1.88$ & 0.58 & 0.932 & 0.569 & 0.867 \\
\hline $\mathrm{a} 37$ & Faith is a strong hold even in hard times & $2.29 \pm 1.49$ & 0.57 & 0.928 & 0.574 & 0.867 \\
\hline $\mathrm{a} 35$ & Trust in a higher power which carries through & $2.24 \pm 1.53$ & 0.56 & 0.864 & 0.548 & 0.868 \\
\hline a39 & Live in accordance with religious convictions & $2.06 \pm 1.48$ & 0.52 & 0.842 & 0.564 & 0.868 \\
\hline a38 & Pray to become healthy again & $2.04 \pm 1.53$ & 0.51 & 0.836 & 0.576 & 0.867 \\
\hline \multicolumn{7}{|c|}{ 2. Conscious and Healthy Living ( $\alpha=0.743 ; 9.0 \%$ of variance) } \\
\hline $\mathrm{a} 2$ & Try to be physically fit & $3.33 \pm 0.84$ & 0.83 & 0.726 & 0.261 & 0.875 \\
\hline a1 & Actively care for healthy diet & $3.20 \pm 0.98$ & 0.80 & 0.715 & 0.290 & 0.874 \\
\hline a3 & Live consciously each and every day & $3.14 \pm 0.88$ & 0.79 & 0.632 & 0.423 & 0.872 \\
\hline a5 & Keep away harmful influences & $3.10 \pm 0.88$ & 0.78 & 0.573 & 0.365 & 0.873 \\
\hline a6 & Change life that I will soon get well & $3.46 \pm 0.91$ & 0.87 & 0.554 & 0.374 & 0.873 \\
\hline $\mathrm{a} 12$ & Reach level of health which is still possible & $3.44 \pm 0.81$ & 0.86 & 0.408 & 0.337 & 0.874 \\
\hline \multicolumn{7}{|c|}{ 3. Reappraisal: Illness as Chance ( $\alpha=0.820 ; 8.9 \%$ of variance) } \\
\hline $\mathrm{a} 43$ & Regard illness as a chance for development & $1.55 \pm 1.35$ & 0.39 & 0.843 & 0.480 & 0.870 \\
\hline $\mathrm{a} 44$ & Without illness would not have valued life & $1.24 \pm 1.24$ & 0.31 & 0.783 & 0.379 & 0.873 \\
\hline $\mathrm{a} 42$ & Reflect on what is essential in life & $2.14 \pm 1.40$ & 0.54 & 0.721 & 0.539 & 0.868 \\
\hline $\mathrm{a} 41$ & Illness has meaning & $1.28 \pm 1.35$ & 0.32 & 0.654 & 0.480 & 0.870 \\
\hline \multicolumn{7}{|c|}{ 4. Perspectives and Positive Attitudes ( $\alpha=0.688 ; 8.8 \%$ of variance) } \\
\hline a9 & Realize shelved dreams and wishes & $2.51 \pm 1.08$ & 0.63 & 0.725 & 0.314 & 0.874 \\
\hline a7 & Do all that what pleases & $2.70 \pm 1.05$ & 0.68 & 0.655 & 0.323 & 0.874 \\
\hline a14 & Take (responsibility for) life in own hands & $3.20 \pm 0.89$ & 0.80 & 0.546 & 0.216 & 0.876 \\
\hline $\mathrm{a} 10$ & Not constantly thinking at illness & $3.30 \pm 1.00$ & 0.83 & 0.544 & 0.247 & 0.875 \\
\hline a8 & Resolve cumbering situations of past & $2.34 \pm 1.21$ & 0.59 & 0.538 & 0.403 & 0.872 \\
\hline a4 & Think positive & $3.39 \pm 1.04$ & 0.85 & 0.431 & 0.286 & 0.874 \\
\hline \multicolumn{7}{|c|}{ 5. Trust in Medical Help ( $\alpha=0.793 ; 8.6 \%$ of variance $)$} \\
\hline $\mathrm{a} 27$ & Take regularly prescribed medicaments & $3.14 \pm 1.36$ & 0.79 & 0.730 & 0.291 & 0.875 \\
\hline a28 & Follow the advices of doctor/therapist & $3.15 \pm 1.15$ & 0.79 & 0.677 & 0.385 & 0.872 \\
\hline a29 & Full confidence in doctors and therapists & $3.19 \pm 0.96$ & 0.80 & 0.659 & 0.325 & 0.874 \\
\hline $\mathrm{a} 22$ & Thoroughly informed about disease & $2.78 \pm 1.32$ & 0.70 & 0.582 & 0.453 & 0.871 \\
\hline \multicolumn{7}{|c|}{ 6. Search for Alternative Help ( $\alpha=0.737 ; 8.2 \%$ of variance) } \\
\hline $\mathrm{a} 25$ & Search for alternative ways of healing & $2.11 \pm 1.41$ & 0.53 & 0.742 & 0.418 & 0.872 \\
\hline $\mathrm{a} 24$ & Find people which can help & $2.32 \pm 1.35$ & 0.58 & 0.738 & 0.441 & 0.871 \\
\hline $\mathrm{a} 23$ & Information how to become healthy again & $2.80 \pm 1.30$ & 0.70 & 0.595 & 0.485 & 0.870 \\
\hline a11 & Do not give up to fight disease & $2.99 \pm 1.18$ & 0.75 & 0.482 & 0.455 & 0.871 \\
\hline
\end{tabular}

Cronbach's alpha $=0.876 ;$ Kaiser-Meyer-Olkin $=0.891$; Varimax rotation with Kaiser normalization (rotation converged in 6 iterations); 6 factors with 39 items explain $57.9 \%$ of variance; item a22 from scale 5 would fit also to scale $6(0.542)$, while item a23 from scale 6 would also fit to scale 5 ( 0.587 ).

The items of the SpREUK and the AKU were scored on a 5-point scale from disagreement to agreement (0: does not apply at all; 1 : does not truly apply; 2: don't know; 3: applies quite a bit; 4: applies very much). The scores were referred to a $100 \%$ level (4 'applied very much' $=100 \%$ ).

The items of the SpREUK-P were scored on a 4-point scale (0: never; 1: seldom; 2: often; 3 : regularly). The respective scores are referred to a $100 \%$ level ( 3 'regularly' $=100 \%$ ), which reflects the degree of an engagement in the distinct forms of an SpR practice ('engagement scores').

Differences in the given scores were tested using ANOVA. We judged $\mathrm{p}<0.05$ significant and $0.05<\mathrm{p}<0.10$ as a trend. To test the impact of several variables on the subscales, we performed analysis of variance (ANOVA). All statistical analyses were performed with SPSS for Windows 12.0.

\section{Results}

\section{Adaptive Coping of Patients with Chronic Diseases}

Most individuals use adaptive coping styles which refer to an internal locus of disease control respectively internal strategy to maintaining health, such as Conscious and Healthy Living and Perspectives and Positive Attitudes (fig. 1), while some patients referred also to external loci of disease control, such as Trust in Medical Help, Search for Alternative Help, and Trust in God's Help. Reappraisal (Illness as Chance) was rejected by most individuals, particularly the healthy individuals. 


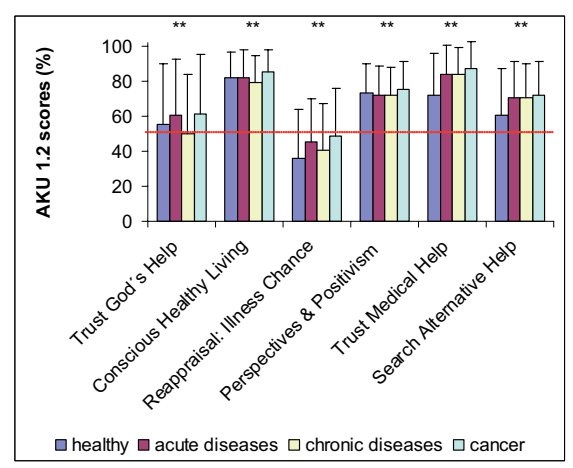

Fig. 1. Adaptive coping styles of individuals from pool 1 . AKU scores $>50 \%$ represent a positive attitude (agreement), while scores $<50 \%$ represent a negative attitude (disagreement); $\mathrm{n}=6,312 ; * * \mathrm{p}<0.001$ (ANOVA).

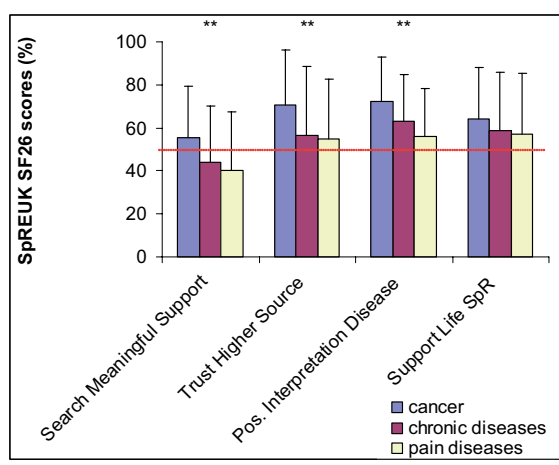

Fig. 2. SpR attitudes and convictions of patients from pool 2. SpREUK scores $>50 \%$ represent a positive attitude (agreement), while scores $<50 \%$ represent a negative attitude (disagreement); $\mathrm{n}=719 ; * * \mathrm{p}<0.001$ (ANOVA).

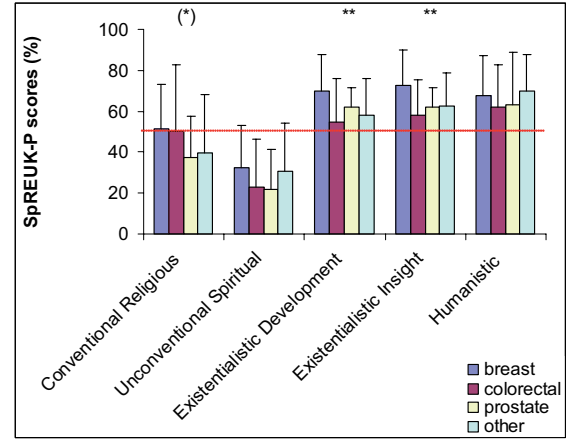

Fig. 3. Forms and frequency of $S p R$ practices of cancer patients from pool 2. SpREUK-P scores $>50 \%$ mean frequent/regular practice, while scores $<50 \%$ mean rare/no practice. $* * \mathrm{p}<0.001 ;(*) 0.05<\mathrm{p}<0.10$ (ANOVA). Tumors were breast cancer (100\% women), colorectal tumors ( $54 \%$ women), prostate cancer (100\% men), and other tumors ( $71 \%$ women).
Analyses of variance revealed that Trust in God's Help was influenced particularly by female gender and higher age (table 2), while the main relevant variable for Conscious and Healthy Living was higher age, for Reappraisal (Illness as Chance) the product of age $\times$ gender, and for Trust in Medical Help age and disease itself.

For the next set of analyses we focused only on cancer patients. Here, female gender was only in trend relevant for Trust in God's Help $(\mathrm{F}=4.079 ; \mathrm{p}=0.044)$ or Perspectives and Positive Attitudes $(\mathrm{F}=5.418 ; \mathrm{p}=0.020)$, while Reappraisal (Illness as Chance) was significantly influenced by the variables gender $(\mathrm{F}=7.269 ; \mathrm{p}=0.007)$ and in trend by gender $\times$ age $(\mathrm{F}=2.585$ $\mathrm{p}=0.037)$. Search for Alternative Help was also significantly influenced by gender $\times$ age $(F=3.933 ; p=0.004)$.

Thus, with respect to the addressed adaptive coping styles, the utilization behavior of cancer patients was mainly influenced by female gender and higher age. Due to the life-threatening character of their disease, they trust powerful external others, such as medical doctors and God.

One may argue that Trust in God's Help should be stronger in reduced health situations. However, in cancer patients the correlation between this factor and SF-12's physical health scale was only weak $(\mathrm{r}=-0.134 ; \mathrm{p}=0.008)$, while psychical health did not correlate with Trust in God's Help ( $\mathrm{r}=0.014$; n.s. $)$.

Among several significant correlations $(0.4>r>0.2 ; p<0.001)$, some strong associations should be highlighted: Trust in God's Help correlated strongly with Reappraisal (Illness as Chance) $(\mathrm{r}=0.477)$, a finding which is in agreement with our previous findings that a positive interpretation of disease can be an SpR issue [6, 18-20]; Perspectives and Positive Attitudes and Conscious and Healthy Living were connected $(r=0.426)$, and Trust in Medical Help with Search for Alternative Help ( $r=0.403)$. From a theoretical point of view these correlations have a rationale, because they fit well to the concepts of an external locus of control (powerful others) respectively internal locus of control (own powers and virtues) $[15,16]$, which were obviously valued by the patients. Thus, several patients with chronic diseases rely on SpR as a source of help, particularly patients with higher age, women, and cancer patients.

\section{SpR Attitudes and Convictions and Forms of Practice of Cancer Patients}

Because we found Reappraisal strongly connected with Trust in God's Help, we intended to further clarify these aspects and investigated patients with cancer and other chronic diseases with the SpREUK questionnaire, which measures Search for Meaningful Support, Trust in Higher Source, Positive Interpretation of Disease (it is possible to interpret illness as an opportunity, a hint to change life, or to reflect upon what is essential in life), and Support in Relations of Life through SpR. When compared to patients with other chronic (pain) diseases, cancer patients were significantly more in Search for Meaningful Support, had Trust in Higher Source and a Positive Interpretation of Disease (fig. 2).

The $\mathrm{SpR}$ attitudes and convictions of cancer patients showed significant differences with respect to gender, SpR self-categorization, and educational level (table 3) Particularly Search for Meaningful Support and Support of Life through SpR were significantly higher in cancer patients with higher educational level. In general, female cancer patients had the highest interest in all SpR categories. Moreover, patients living alone or widowed had higher Trust in Higher Source than patients living with a partner or divorced $(\mathrm{F}=2.667 ; \mathrm{p}=0.034)$. Younger patients (30-49 years of age) had significantly higher Positive Interpretation of Disease than patients within the age groups $50-69$ and $>70$ years $(F=5.286 ; p=0.006)$. However, there 
Table 2. Univariate variance analyses of patients with chronic diseases (pool 1)

\begin{tabular}{|c|c|c|c|}
\hline AKU factors & Variables & F-value & Significance $^{1}$ \\
\hline Trust in God's & gender & 10.848 & $<0.001$ \\
\hline \multirow[t]{3}{*}{ Help } & age group & 7.451 & $<0.001$ \\
\hline & disease group & 3.007 & 0.029 \\
\hline & educational level & 1.127 & n.s. \\
\hline Conscious and & gender & 0.121 & n.s. \\
\hline \multirow[t]{3}{*}{ Healthy Living } & age group & 9.231 & $<0.001$ \\
\hline & disease group & 3.563 & 0.014 \\
\hline & educational level & 2.271 & 0.034 \\
\hline \multirow{5}{*}{$\begin{array}{l}\text { Reappraisal: Illness } \\
\text { as Chance }\end{array}$} & gender & 4.908 & 0.027 \\
\hline & age group & 0.173 & n.s. \\
\hline & disease group & 2.923 & 0.033 \\
\hline & educational level & 1.188 & n.s. \\
\hline & gender $\times$ age group & 2.925 & 0.008 \\
\hline Perspectives and & gender & 1.340 & n.s. \\
\hline \multirow[t]{3}{*}{ Positive Attitudes } & age group & 1.012 & n.s. \\
\hline & disease group & 1.300 & n.s. \\
\hline & educational level & 1.163 & n.s. \\
\hline Trust in Medical & gender & 0.150 & n.s. \\
\hline \multirow[t]{3}{*}{ Help } & age group & 6.438 & $<0.001$ \\
\hline & disease group & 4.907 & 0.002 \\
\hline & educational level & 0.595 & n.s. \\
\hline Search for & gender & 1.657 & n.s. \\
\hline Alternative & age group & 0.460 & n.s. \\
\hline \multirow[t]{2}{*}{ Help } & disease group & 1.730 & n.s. \\
\hline & educational level & 0.482 & n.s. \\
\hline
\end{tabular}

${ }^{1}$ Levene's test for equality of variances was significant in all cases, and thus the level of significance should be $p<0.01$; in this case $p<0.05$ should be regarded as a trend. Here, only significant products of the respective variables were presented.

were no significant differences with respect to duration of disease (data not shown).

Because we observed that female gender was a significant variable, we analyzed the $\mathrm{SpR}$ convictions and attitudes in cancer patients with respect to gender and tumor (table 3), i.e. breast cancer $(100 \%$ women), colorectal tumors $(54 \%$ women), prostate cancer ( $100 \%$ men), and other tumors ( $71 \%$ women). Male patients with prostate cancer were not in Search for Meaningful Support and had minor Positive Interpretation of Disease, while women with breast cancer had the highest scores in these categories. With the exception of Trust in Higher Source, the level of interest in the SpREUK domains was highly associated with the proportion of women in the population.

Variance analyses revealed that for the cancer patients the SpR self-categorization was the most important variable with respect to Search for Meaningful Support $(F=6.205 ; \mathrm{p}=0.001)$ and Trust in Higher Source $(F=24.951 ; p<0.001)$, while gender, age group, educational level, or duration of disease had no significant impact. Support of Live Relations through SpR was in trend influenced by the educational level $(\mathrm{F}=3.578$; $p=0.021)$. However, this SpR self-categorization differs with respect to gender: Most female cancer patients regarded themselves as $\mathrm{R}+\mathrm{S}+(39 \%), 33 \%$ as $\mathrm{R}+\mathrm{S}-, 13 \%$ as $\mathrm{R}-\mathrm{S}+$, and $15 \%$ as $\mathrm{R}-\mathrm{S}-$. In contrast, nearly half of the male cancer patients judged themselves as $\mathrm{R}+\mathrm{S}-(49 \%)$, nearly $1 / 3$ as $\mathrm{R}-\mathrm{S}-$ (27\%), $14 \%$ as $\mathrm{R}+\mathrm{S}+$, and $10 \%$ as $\mathrm{R}-\mathrm{S}+$. These gender-specific differences were statistically significant $(\mathrm{p}=0.006$; Pearson chi-square).

While it is obvious that R-S- cancer patients have no Trust in Higher Source, are not in Search for Meaningful Support, and do not regard $\mathrm{SpR}$ as helpful in relations with life and illness (table 3), they nevertheless do have a Positive Interpretation of Disease. This unique aspect of $\mathrm{SpR}$ is vital in this group too. This factor correlated significantly with Search for Meaningful Support $(r=0.419)$, but to a weaker extent with Trust in Higher Source $(r=0.211)$, and thus is much more a spiritual issue than a religious. To underline this note, we correlated frequency and forms of different SpR practices (as measure with the SpREUK-P) with Positive Interpretation of Disease and found significant $(p<0.001)$ correlations with Existentialistic Insight Practice $(r=0.440)$ and Unconventional Spiritual Practice $(\mathrm{r}=0.338)$, but not with Conventional Religious Practice $(\mathrm{r}=0.119 ; \mathrm{n} . \mathrm{s}$.). This is in accordance with our previous findings [22].

And which forms of SpR practice do cancer patients use? The highest engagement scores were found for existentialistic and humanistic forms of practice (fig. 3), while the interest in Conventional Religious Practice was just moderate, and none of the cancer patients were intensively engaged in Unconventional Spiritual Practices (i.e. meditation). Breast cancer patients were significantly more engaged in the existentialistic forms of SpR practice than the other cancer patients, even more than the patients of the group with 'other tumors', which comprised $71 \%$ women. However, male cancer patients had significantly lower interest in Conventional Religious Practice than female patients (data not shown). Thus, it is not the category 'breast cancer' which predicts interest in SpR issues, but female gender with its specific differences in the SpR self-categorization as the main relevant variable.

\section{Discussion}

Spirituality gains more and more attraction in health care because research has confirmed its potential to prevent, cope with or heal illness [1-13]. Although our work has shown that several patients with chronic diseases rely on distinct aspects of $\mathrm{SpR}$, most patients rely particularly on humanistic and nature-oriented practices, rather than on a conventional religious or an unconventional spiritual practice (reviewed in [22]). Large groups of patients do not regard themselves as religious or spiritual and do not have any interest in SpR topics: $39 \%$ reported themselves as $\mathrm{R}-\mathrm{S}-, 34 \%$ as $\mathrm{R}+\mathrm{S}-, 19 \%$ as $\mathrm{R}+\mathrm{S}+$, and $8 \%$ as $\mathrm{R}-\mathrm{S}+[20]$. In patients with multiple sclero- 
Table 3. Mean values of SpREUK score in cancer patients (pool 2)

\begin{tabular}{|c|c|c|c|c|}
\hline & $\begin{array}{l}\text { Search for } \\
\text { Meaningful } \\
\text { Support }\end{array}$ & $\begin{array}{l}\text { Trust in } \\
\text { Higher } \\
\text { Source }\end{array}$ & $\begin{array}{l}\text { Positive } \\
\text { Interpretation } \\
\text { of Disease }\end{array}$ & $\begin{array}{l}\text { Support of Life } \\
\text { through SpR }\end{array}$ \\
\hline All tumor patients & $55.3 \pm 24.0$ & $70.4 \pm 25.8$ & $72.1 \pm 21.1$ & $63.9 \pm 24.1$ \\
\hline \multicolumn{5}{|l|}{ Tumor localization } \\
\hline Breast (46\%) & $59.9 \pm 24.6$ & $71.6 \pm 25.4$ & $79.6 \pm 19.1$ & $67.3 \pm 24.3$ \\
\hline Colorectal (14\%) & $50.4 \pm 21.2$ & $73.3 \pm 23.2$ & $64.7 \pm 20.1$ & $62.5 \pm 28.4$ \\
\hline Prostate $(13 \%)$ & $40.1 \pm 15.2$ & $67.5 \pm 28.7$ & $55.9 \pm 19.8$ & $53.9 \pm 16.9$ \\
\hline Other $(27 \%)$ & $58.0 \pm 25.1$ & $68.3 \pm 26.7$ & $71.2 \pm 19.9$ & $64.4 \pm 23.9$ \\
\hline F-value & 5.100 & 0.374 & 10.818 & 1.851 \\
\hline $\mathrm{p}$-value & 0.002 & n.s. & $<0.001$ & n.s. \\
\hline \multicolumn{5}{|l|}{ Gender } \\
\hline Female $(73 \%)$ & $59.7 \pm 24.3$ & $72.7 \pm 25.0$ & $76.4 \pm 19.6$ & $67.2 \pm 24.2$ \\
\hline Male (27\%) & $45.2 \pm 21.2$ & $65.6 \pm 27.0$ & $60.1 \pm 19.9$ & $56.6 \pm 22.3$ \\
\hline F-value & 13.753 & 2.844 & 24.516 & 6.394 \\
\hline p-value & $<0.001$ & n.s. & $<0.001$ & 0.012 \\
\hline \multicolumn{5}{|l|}{ Education level } \\
\hline Secondary school (25\%) & $49.3 \pm 25.9$ & $71.6 \pm 27.3$ & $64.1 \pm 22.7$ & $60.4 \pm 24.0$ \\
\hline Junior high school $(25 \%)$ & $52.6 \pm 23.6$ & $75.2 \pm 26.6$ & $74.6 \pm 19.9$ & $56.5 \pm 26.6$ \\
\hline High school (35\%) & $66.4 \pm 21.9$ & $72.8 \pm 21.9$ & $72.8 \pm 21.1$ & $73.1 \pm 20.3$ \\
\hline Other $(15 \%)$ & $62.0 \pm 23.9$ & $66.8 \pm 22.3$ & $76.3 \pm 20.3$ & $68.5 \pm 18.8$ \\
\hline F-value & 3.834 & 0.478 & 1.814 & 3.271 \\
\hline p-value & 0.012 & n.s. & n.s. & 0.024 \\
\hline \multicolumn{5}{|l|}{ SpR self-categorization } \\
\hline $\mathrm{R}+\mathrm{S}+(32 \%)$ & $73.3 \pm 19.3$ & $85.0 \pm 14.4$ & $78.2 \pm 18.2$ & $78.7 \pm 15.1$ \\
\hline $\mathrm{R}+\mathrm{S}-(38 \%)$ & $48.6 \pm 21.1$ & $81.3 \pm 17.0$ & $68.2 \pm 20.5$ & $62.4 \pm 22.6$ \\
\hline $\mathrm{R}-\mathrm{S}+(12 \%)$ & $64.9 \pm 13.7$ & $52.5 \pm 18.2$ & $76.4 \pm 21.9$ & $67.0 \pm 17.4$ \\
\hline R-S- $(18 \%)$ & $32.6 \pm 17.7$ & $36.4 \pm 22.3$ & $65.1 \pm 23.0$ & $32.6 \pm 20.2$ \\
\hline F-value & 37.870 & 73.073 & 4.235 & 31.913 \\
\hline p-value & $<0.001$ & $<0.001$ & 0.001 & $<0.001$ \\
\hline
\end{tabular}

Results of the 180 cancer patients are means \pm standard deviation. Deviations $>15 \%$ from the mean of the respective group of patients with chronic diseases are highlighted in italics. sis, we observed $36 \% \mathrm{R}-\mathrm{S}-$ patients, $41 \% \mathrm{R}+\mathrm{S}-, 16 \% \mathrm{R}+\mathrm{S}+$, and $7 \% \mathrm{R}-\mathrm{S}+$ (Büssing et al., in preparation). In this study we had a relevant fraction of $\mathrm{R}-\mathrm{S}-$ cancer patients $(15 \%$ of women, $27 \%$ of men), too.

It is obvious that the interest in institutional religion declines, but that the interest in a noninstitutional spirituality increases. Particularly health carers and chaplains have to adapt to changing conceptual frameworks of spirituality. However, it is unclear which aspects of the multidimensional construct 'spirituality' are vital at all. In a recent study we confirmed 7 main factors to describe unique aspects of spirituality, i.e. prayer, trust in God and shelter; insight, awareness and wisdom; transcendence conviction; compassion, generosity and patience; conscious interactions (with others, self, nature); equanimity and meditation; gratitude, reverence and respect [22, 25]. One has to assume complex interconnections of various existing views, attitudes and concepts, and therefore, an oversimplification of spiritual concerns is not appropriate.

From a conceptual point of view, one should differentiate between spirituality in religion, which has the connotation of a more open, individual and pluralistic faith, and spirituality as opposed to religion, and thus defining it as a bunch of multiple but individual 'paths' to the one truth. As described previously, we primarily referred to distinct topics found in the patients we met for example in the tumor outpatient clinic [17-20, 26]. These chronic patients were in search for hold and connection, and in search for meaning. Thus, we conceptualized spirituality as an attitude of search for meaning, and religiosity as an attitude of reference, trust and hold. Several patients argued that they regard their illness as a 'hint' to change life, to behave differently etc. [17]. Particularly this Positive Interpretation of Disease (resp. Reappraisal: Illness as Chance) was highlighted to be of outstanding importance for patients with severe diseases $[6,19]$, because it is a measure independent of any religion or specific belief. The respective factors obviously refer to an appraisal coping, but are nevertheless a specifically spiritual issue, which is associated with the Meaning domain of Martsolf and Mickley [27], and thus was found to correlate well with an Existentialistic Practice and strongly with Search for Meaningful Support [6, 22]. Nevertheless, even patients without an explicit interest in SpR can interpret illness as an opportunity to change life or to reflect upon what is essential 
in life. This fact has to be taken into account for conventional cancer care and might be an opportunity to widen the perspective of these patients in the psycho-emotional struggle with their disease.

In fact, we found that women, particularly with breast cancer, had significantly higher Trust in Higher Source and a Positive Interpretation of Disease than other cancer patients, particularly men. There were no correlations between duration of disease and $\mathrm{SpR}$ issues, and only a weak negative correlation with physical health. Also Albani et al. [28], which analyzed religion as a potential protective factor regarding body complaints in an elderly German population, reported that women had higher scores on religiosity than men, but there were no significant correlations between religiosity and body complaints. Thus, the situation in Europe, at least Germany, may differ from that of other countries, particularly North America, where close to $90 \%$ of patients over age 60 depend on religion to cope [29]. Moreover, in German breast cancer patients Zwingmann et al. [30] found that the relationship between religious coping and psychosocial outcomes was completely mediated by nonreligious coping, whereby only depressive coping and not active problem-focused coping proved to be a mediating variable.

However, in patients with chronic pain diseases we confirmed moderate correlations between Support of Life through SpR with life satisfaction aspects (self: $r=0.359$; future prospects: $r=0.381)$ and Trust in Higher Source with life satisfaction (self: $r=0.235$; future prospects: $r=0.223$ ), while the aspects family life, friends, work, living area or financial situation did not correlate with any of the SpREUK factors [31].

The measurement of quality of life is based on the persons' perspective of their overall quality of life and their assessment of specific components of quality of life (i.e., physical, psychological, and social well-being) [32]. Spiritual wellbeing is a subjective and multidimensional construct too, which shares several aspects of psychosocial well-being. Because several research instruments rely on different concepts of spirituality which may sum up various measures of spirituality (i.e., convictions, attitudes, engagement, etc.), it is unclear which aspect of $\mathrm{SpR}$ (i.e., existential respectively relational or transcendent measures of spirituality) correlates with which aspect of quality of life (i.e., disease-specific, global, unidimensional or multiple dimensions of quality of life respectively life satisfaction or well-being). Thus, although the relationship between spirituality and various dimensions of health and quality of life has been extensively examined during the past decade, no clear conclusions can be drawn. However, a recent meta-analysis of the relationship between spirituality and quality of live categorized the different measures and confirmed a moderate effect size between spirituality and quality of life [33]. The results of Sawatzky et al. [33] revealed several findings that support the conceptualization of spirituality as a distinct concept that relates to quality of life.
Nevertheless, clinicians caring for older patients should consider inquiring about spirituality and religious coping as a way of improving outcomes, and thus the higher spiritual needs of cancer patients should be valued. One may assume that SpR beliefs provide a helpful active-cognitive framework for cancer patients from which to face the existential crises of lifethreatening illness. Thus, SpR may help one to adapt by finding meaning, hope, and coherence in illness, albeit it is still controversial whether SpR causes health or is an effect of well-being.

However, health policies focus on fast access to healing and throughput, and thus addressing spiritual needs may not be practical for health professionals. Regardless of their own belief system, physicians should not allow their own bias to blind them to the possibility that $\mathrm{SpR}$ beliefs play an important role for many of their patients. On the other hand, SpR should not be reduced to that function of 'last hope', which remains when doctors, psychologists, social workers etc. have left the patient. Research indicates that health professionals can play an important role in enhancing psychospiritual well-being, i.e. selfawareness, coping and adjusting effectively with stress, relationships, sense of faith, sense of empowerment and confidence, and living with meaning and hope [34]. Balboni et al. [35] resumed that nearly half of advanced cancer patients reported that their spiritual needs were minimally or not at all supported by a religious community and that $72 \%$ reported that their spiritual needs were minimally or not at all supported by the medical system. Because this spiritual support was significantly associated with the patients' quality of life, Balboni's note is of outstanding relevance for caregivers, who are in most cases not prepared to face these needs. In fact, a current study [31] with chronic pain patients showed that $25 \%$ would like to talk with a priest about their SpR needs, $25 \%$ mentioned that they have no partner to talk about these needs, and for $43 \%$ it is important to talk with their medical doctor about it - but he is not prepared and might not be willing to do this job.

A recent study investigated the process of spiritual development in women diagnosed with cancer within five years of initial treatment and emphasized not only the importance of spirituality, but also that spiritual experience is individualized and developmental in nature [36]. Halstead and Hull [36] advised that spiritual caregiving requires an acknowledgment of need by the woman with cancer and a caring, sensitive caregiver to address individual needs of women with cancer that may vary over time.

\section{Acknowledgements}

We are grateful to 'Die Continentale Versicherung' for their support and to Dr. Cristina Stumpf, Dr. Mette Kaeder, Hans-Joachim Balzat, PD Dr. Andreas Michalsen and Nadja Keller for encouraging their patients to participate in our studies. 


\section{References}

1 Koenig HG, Larson DB, Larson SS: Religion and coping with serious medical illness. Ann Pharmacother 2001;35:352-359.

2 Sloan RP, Bagiella E: Claims about religious involvement and health outcomes. Ann Behav Med 2002;24:14-21.

3 McClain CS, Rosenfeld B, Breitbart W: Effect of spiritual well-being on end-of-life despair in terminally-ill cancer patients. Lancet 2003;361:16031607.

4 Sloan RP, Bagiella E, Powell T: Religion, spirituality, and medicine. Lancet 1999:353:664-667.

5 McIllmurray MB, Francis B, Harman JC, Morris SM, Soothill K, Thomas C: Psychosocial needs in cancer patients related to religious belief. Palliat Med 2003;17:49-54.

6 Büssing A, Ostermann T, Koenig HG: Relevance of spirituality and religion in German patients with chronic diseases. Int J Psychiatry Med 2007;37: 39-57.

7 Koenig HG: Integrating spirituality into medical practice: a new era in medicine; in Büssing $\mathrm{A}$ Ostermann T, Glöckler M, Matthiessen PF (eds) Spiritualität, Krankheit und Heilung - Bedeutung und Ausdrucksformen der Spiritualität in der Medizin. Frankfurt, Verlag für Akademische Schriften, 2006, pp 232-241.

8 Pargament KI, Koenig HG, Tarakeshwar N, Hahn $\mathrm{J}$ : Religious struggle as a predictor of mortality among medically ill elderly patients: a two-year longitudinal study. Arch Intern Med 2001;161: 1881-1885.

$\checkmark$ Levine EG, Targ E: Spiritual correlates of functional well-being in women with breast cancer. Integr Cancer Ther 2002;1:166-174.

10 Fehring RJ, Miller JF, Shaw C: Spiritual well-being, religiosity, hope, depression, and other mood states in elderly people coping with cancer. Oncol Nurs Forum 1997;24:663-671.

11 McGrath P: Spirituality and discourse: a postmodern approach to hospice research. Aust Health Rev 1997;20:116-128.

12 Nelson CJ, Rosenfeld B, Breitbart W, Galietta M: Spirituality, religion, and depression in the terminally ill. Psychosomatics 2002;43:213-220.
Williams AL: Perspectives on spirituality at the end of life: a meta-summary. Palliat Support Care 2006; 4:407-417.

14 Emmons RA, Cheung C, Tehrani K: Assessing spirituality through personal goals: implications for research on religion and subjective well being. Soc Indicators Res 1998;45:391-422.

15 Rotter J: Generalized expectations for internal versus external control reinforcement. Psychol Monogr: Gen Appl Psychol 1966;80:1-27.

16 Levenson H: Multidimensional locus of control in psychiatric patients. J Consult Clin Psychol 1973;41: 397-404.

17 Büssing A, Ostermann T, Matthiessen PF: Role of religion and spirituality in medical patients in Germany. J Relig Health 2005;44:321-340.

18 Büssing A, Ostermann T, Matthiessen PF: Search for meaningful support and the meaning of illness in German cancer patients. Anticancer Res 2005; 25:1449-1455.

19 Büssing A, Ostermann T, Matthiessen PF: Role of religion and spirituality in medical patients - confirmatory results with the SpREUK questionnaire. Health Qual Life Outcomes 2005;3:10.

20 Büssing A, Keller N, Michalsen A, Moebus S, Dobos G, Ostermann T, Matthiessen PF: Spirituality and adaptive coping styles in German patients with chronic diseases in a CAM health care setting. J Complement Integr Med 2006;3:4.

21 Büssing A, Ostermann T, Koenig HG: Relevance of religion and spirituality in German patients with chronic diseases. Int J Psychiatry Med 2007;37: 39-57.

22 Büssing A, Ostermann T, Glöckler M, Matthiessen PF: Spiritualität, Krankheit und Heilung - Bedeutung und Ausdrucksformen der Spiritualität in der Medizin. Frankfurt, Verlag für Akademische Schriften, 2006.

23 Büssing A, Matthiessen PF, Ostermann T: Engagement of patients in religious and spiritual practices: confirmatory results with the SpREUK-P 1.1 questionnaire as a tool of quality of life research. Health Qual Life Outcomes 2005;3:53.

24 Büssing A, Matthiessen PF, Ostermann T: The AKU questionnaire as a research tool in CAM. Focus Altern Complement Ther 2006;11:8.
5 Büssing A, Ostermann T, Matthiessen PF: Distinct expressions of vital spirituality. The ASP questionnaire as an explorative research tool. J Relig Health 2007; 46:267-286.

26 Ostermann T, Büssing A, Matthiessen PF: Pilotstudie zur Entwicklung eines Fragebogens zur Erfassung spiritueller und religiöser Einstellung und des Umgangs mit Krankheit (SpREUK). Forsch Komplementärmed Klass Naturheilkd 2004;11:346-353.

27 Martsolf DS, Mickley JR: The concept of spirituality in nursing theories: differing world-views and extent of focus. J Adv Nurs 1998;27:294-303.

28 Albani C, Bailer H, Grulke N, Geyer M, Brahler E: Religiosity and spirituality in the elderly. Z Gerontol Geriatr 2004;37:43-50.

29 Koenig HG: Religious beliefs and practices of hospitalized medically ill older adults. Int J Geriatr Psychiatry 1998;13:213-224.

30 Zwingmann C, Wirtz M, Muller C, Korber J, Murken S: Positive and negative religious coping in German breast cancer patients. J Behav Med 2006; 29:533-547.

31 Büssing A, Balzat HJ, Ostermann T: Spirituality/religiosity, life satisfaction and disease perception in patients with chronic pain diseases (PG7-03). Forsch Komplementärmed 2007;14(suppl 1):44.

32 Mytko JJ, Knight SJ: Body, mind and spirit: towards the integration of religiosity and spirituality in cancer quality of life research. Psychooncology 1999;8:439-450.

33 Sawatzky R, Ratner PA, Chiu L: A meta-analysis of the relationship between spirituality and quality of life. Soc Indicators Res 2005;72:153-188.

34 Lin HR, Bauer-Wu SM: Psycho-spiritual well-being in patients with advanced cancer: an integrative re view of the literature. J Adv Nurs 2003;44:69-80.

35 Balboni TA, Vanderwerker LC, Block SD, Paulk ME, Lathan CS, Peteet JR, Prigerson HG: Religiousness and spiritual support among advanced cancer patients and associations with end-of-life treatment preferences and quality of life. J Clin Oncol 2007;25:555-560.

36 Halstead MT, Hull M: Struggling with paradoxes: the process of spiritual development in women with cancer. Oncol Nurs Forum 2001;28:1534-1544. 